\title{
PENGEMBANGAN ALAT EKSPERIMEN PENENTUAN KOEFISIEN GAYA GESEK PADA BIDANG MIRING BERBASIS INDUKSI MAGNET
}

\author{
Novi Yola Saiputri ${ }^{1 *}$, Thoha Firdaus ${ }^{1}$, Fatkhur Rohman ${ }^{1}$ \\ ${ }^{1}$ Universitas Nurul Huda Sukaraja OKU Timur \\ *Coressponding author: noviyolasaiputri@gmail.com
}

\begin{abstract}
Article History:
Received: Oktober 10, 2021

Revised: November 01, 2021

Accepted: Desember 01, 2021

Published: Desember 31, 2021

Keyword: Friction coefficient, magnetic induction, tool development
\end{abstract}

Abstract: This study aims to develop an experimental tool for determining the coefficient of kinetic friction on an inclined plane based on magnetic induction. The object of material used to find the value of the coefficient of kinetic friction is acrylic with wood, acrylic with acrylic, and acrylic with plastic. To determine the value of the coefficient of kinetic friction, a $620 \mathrm{~g}$ load was launched on a plane surface with an angle of $30^{\circ}$ and a neodymium magnet with three solenoid coils was placed on an inclined plane to capture the magnetic induction wave signal displayed by Audacity as the generated time logging data. The development model in this study is the Plomp model. The first stage is preliminary research, the second stage is Design and Develop prototype. The results of this study indicate the validity value obtained from experimental tools and support systems with an average validation index of 0.86 with high validity criteria. While the results of the practicality test by the teacher obtained an average percentage of $82 \%$ with appropriate criteria, while the practicality test by students obtained a percentage of $78.33 \%$ with appropriate criteria. The percentage of relative error between acrylic and wood was $15 \%$ with a coefficient of kinetic friction $\mu \_k 0.292$, acrylic with acrylic 30\% $\mu \_k \quad 0.2080 .208$ and acrylic with plastic obtained $\mu \_k \quad 0.265$. Based on these data, it can be concluded that the experimental tool for determining the coefficient of kinetic friction developed is valid and practical to be used as a learning media.

Abstrak: Penelitian ini bertujuan untuk mengembangkan alat eksperimen penentuan koefisien gesek kinetis pada bidang miring berbasis induksi magnet. Objek bahan yang digunakan untuk mencari nilai koefisien gesek kinetis adalah akrilik dengan kayu, akrilik dengan akrilik dan akrilik dengan plastik. Mengetahui nilai koefisien gesek kinetis dengan meluncurkan beban seberat 620 gr pada permukaan bidang dengan sudut kemiringan $30^{\circ}$ dan diletakkan magnet neodymium dengan tiga lilitan solenoida pada bidang miring untuk menangkap sinyal gelombang induksi magnet yang ditampilkan oleh audacity sebagai data logging waktu yang dihasilkan. Model pengembangan dalam penelitian ini adalah model Plomp. Tahap pertama adalah preliminary research, tahap kedua Design and Develop prototype. Hasil penelitian ini menunjukkan nilai validitas yang diperoleh dari alat eksperimen dan sistem pendukung dengan ratarata indeks validasi 0,86 dengan kriteria validitas tinggi. Sedangkan hasil uji kepraktisan oleh guru diperoleh rata-rata persentase $82 \%$ dengan kriteria layak sedangkan uji kepraktisan oleh peserta didik diperoleh persentase 78,33\% dengan kriteria layak. Persentase Ralat relatif akrilik dengan kayu diperoleh sebesar $15 \%$ dengan nilai koefisien gesek kinetis $\mu_{k} 0.292$, akrilik dengan akrilik $30 \% \mu_{k} 0.208$ dan akrilik dengan plastik diperoleh $\mu_{k} \quad 0.265$. Berdasarkan data tersebut dapat disimpulkan bahwa alat eksperimen penentuan koefisien gesek kinetis yang dikembangkan bersifat valid dan praktis untuk digunakan sebagai media pembelajaran oleh pengguna. 


\section{PENDAHULUAN}

Pendidikan adalah usaha sadar dan terencana untuk mewujudkan suasana belajar dan proses pembelajaran agar peserta didik secara aktif mengembangkan potensi dirinya untuk memiliki kekuatan spiritual, keagamaan, pengendalian diri, kepribadian, akhlak mulia, serta keterampilan yang diperlukan dirinya, masyarakat, bangsa dan Negara (Kebudayaan, 2003). Menurut Suyatno (2009) sebuah perubahan dalam pendidikan dapat dilihat dari pergeseran paradigma dari teaching kepada learning, perubahan dari pemahaman mono kecerdasan kepada multi kecerdasan anak, pergantian pusat pembelajaran dari berpusat kepada guru menjadi berpusat kepada peserta didik, pergantian pola mengajar deduktif kepada induktif, dan pembelajaran lebih mengarah kepada tindakan.

Pendidikan juga dapat diartikan sebagai membina kepribadiaan manusia sesuai dengan nilai-nilai dalam masyarakat dan kebudayaannya (Djamaluddin, 2014), pendidikan juga dapat diartikan sebagai usaha untuk menyadarkan perkembangan manusia untuk menuju kedewasaan (Walid, 2017). Kualitas kepribadian seseorang dapat ditingkatkan melalui pendidikan, pemerintah selalu berupaya untuk meningkatkan kualitas pendidikan melalui berbagai kebijakan, antara lain kebijakan sertifikasi guru dan dosen, bantuan operasional sekolah, pemberian block grant dan menetapkan Standar Nasional Pendidikan (Rakhmawati et al., 2016).

Pesatnya perkembangan ilmu pengetahuan khususnya Sains (IPA) dan teknologi, banyak memberikan manfaat bagi penyediaan kebutuhan manusia, cepatnya perkembangan teknologi yang berada di pasaran sangat membuat daya saing sehingga perkembangan ilmu pengetahuan dan teknologi memiliki perkembangan yang sangat cepat dan menjadi nilai pendorong untuk menciptakan nilai tambah dalam pengetahuan sehingga pendidik berperan sangat besar dalam proses pembelajaran dan mengikut sertakan teknologi dalam proses pembelajaran (Aini et al., 2021). Dalam Pendidikan lama lebih mengedepankan pengajaran "3R" yaitu reading, writing and arithmetic sehingga pembelajaran kurang menarik (Alismail \& McGuire, 2015). Tingginya tuntutan dalam pendidikan dan mutu lulusan pendidikan dan pesatnya perkembangan ilmu pengetahuan dan teknologi secara langsung berdampak terhadap pendidik dalam merencanakan dan melaksanakan pembelajaran (Harahap et al., 2021).

Dunia pendidikan sudah memasuki dunia media, dimana kegiatan pembelajaran lebih diutamakan melalui media dan dituntut untuk mengurangi kegiatan ceramah dalam proses belajar (Nurseto, 2012). Pemanfaatan media seperti modul, laptop/komputer, video pembelajaran dan masih banyak lagi yang belum maksimal digunakan dalam kegiatan pembelajaran di sekolah (Irwandani et al., 2017). Dalam kehidupan sehari-hari, di lingkungan sekitar tersedia beragam media pembelajaran yang dapat mendukung proses belajar siswa.

Pemanfaatan media seperti modul, laptop/komputer, video pembelajaran dan masih banyak lagi yang belum maksimal digunakan dalam kegiatan pembelajaran di sekolah (Astuti et al., 2018). Modul yang sering kita jumpai dalam proses pembelajaran adalah modul praktikum konvensional (Muzaky \& Handhika, 2015).

Modul praktikum konvensional adalah modul praktikum yang hanya megedepankan pernyataan instruksional sehingga siswa bekerja hanya sesuai 
perintah yang terdapat dalam modul dan siswa tidak diizinkan lebih leluasa dalam pemahaman sebuah konsep dalam materi belajar tersebut (Mardianti et al., 2020), modul praktikum merupakan sarana yang dibutuhkan dalam proses pembelajaran saat di laboratorium agar kegiatan praktikum berjalan dengan lancar, agar sesuai dengan tujuan yang ingin dicapai, memperkecil resiko yang akan terjadi saat kegiatan praktikum berlangsung sehingga modul praktikum sangatlah dibutuhkan saat proses pembelajaran yang dilakukan di laboratorium (Widayanti et al., 2018).

Berdasarkan observasi yang telah dilakukan di Sekolah Menengah Kejuruan (SMK) Negeri 1 Buay Pemuka Bangsa Raja media pembelajaran yang sering digunakan oleh sebagian guru pada mata pelajaran fisika masih menggunakan papan tulis dan media modul yang disediakan oleh pihak sekolah. Seiring dengan kebutuhan teknologi yang sangat berkembang dengan cepat, banyak sekali media pembelajaran yang dapat digunakan dalam kegiatan pembelajaran seperti laptop, alat eksperimen modul interaktik. Software yang berkembang pada saat ini, dan salah satu diantaranya adalah Audacity (Leman \& Lubis, 2021). Audacity dapat direkomendasikan sebagai salah satu software media pembelajaran fisika yang mampu memfasilitasi penyelidikan data yang berkaitan dengan materi bunyi dan beberapa penyelidikan tentang Elektromagnetic Field (EMF) (Rohman et al., 2020).

Pada penelitian terdahulu yang berjudul "Measurement of kinetic friction coefficient through magnetic induction using audacity application in physic learning" (Rohman et al., 2020). Dalam penelitiannya merancang alat eksperimen pengukuran koefisien gesek kinetik bahan melalui induksi magnet menggunakan aplikasi audacity, objek bahan yang akan diukur koefisien gesek kinetik adalah akrilik kasar dengan kayu pada sistem gerak massa benda $\mathrm{m}_{1}$ dan $\mathrm{m}_{2}$ yang terhubung melalui katrol pada meja.

Pada penelitian terdahulu berjudul "Pengaruh luas permukaan benda terhadap koefisien gesek statis dan kinetis pada bidang miring dengan menggunakan video tracker" dalam penelitian ini hanya menganalisis pengaruh luas permukaan benda terhadap koefisien gesek statis dan kinetis dan tanpa pengaturan sudut (Amirudin et al., 2018). Selanjutnya penelitian yang berjudul "Miskonsepsi gaya gesek pada mahasiswa", dalam penelitiannya dilakukan analisis dan evaluasi terhadap konsep gaya gesek dan diberikan pelurusan materi mengenai konsep gaya gesek (Tiandho, 2018). Pada penelitian berjudul "Pengujian koefisien gesek permukaan plat baja ST 37 pada bidang miring terhadap viskositas pelumas dan kekasaran permukaan", dimana dalam penelitiannya bertujuan untuk menganalisis koefisien gesek permukaan terhadap viskositas pelumas pada bidang miring (Fitrianto et al., 2015).

Dari beberapa penelitian terdahulu belum adanya pengukuran koefisien gaya gesek pada bidang miring berbasis induksi magnet dan belum adanya penelitian yang menggunakan bahan praktikum akrilik dan kayu. Penelitian ini berfokus pada pengukuran koefisien gaya gesek pada bidang miring berbasis induksi magnet dengan bantuan software Audacity yang dapat digunakan dalam proses pembelajaran. Software Audacity yang dapat membaca sinyal gelombang dari induksi magnet pada solenoida yang dihasilkan oleh sistem gerak massa 
benda bidang miring dimanfaatkan sebagai metode data logging untuk pengambilan waktu pengukuran koefisien gaya gesek kinetis. Solenoida diletakkan dibawah lintasan meja, sementara massa yang ditempeli magnet begerak sepanjang lintasan tertentu. Saat massa dan magnet bergerak melintasi solenoida, maka akan memicu munculnya sinyal medan magnet yang data waktunya dapat terekam pada Audacity. Koefisien gaya gesek yang diselidiki pada penelitian ini adalah koefisien gaya gesek kinetis akrilik dengan kayu, akrilik dengan plastik dan akrilik dengan akrilik pada bidang miring yang jaraknya dapat di variasikan dengan jarak yang digunakan $10 \mathrm{~cm}$ dan $5 \mathrm{~cm}$ dengan sudut kemiringan $30^{\circ}$.

\section{METODE PENELITIAN}

Jenis penelitian yang digunakan adalah penelitian pengembangan model Plom and Nieven yang bertujuan menghasilkan suatu produk. Model pengembangan penelitian ini terdiri dari tiga fase: preliminary research (penelitian terdahulu), Design and develop prototype (desain dan pengembangan prototipe), dan Assessment phase (tahap penilaian) (Plomp, 2013). Namun pada penelitian ini hanya sampai dengan tahap Design and develop prototype dengan tujuan untuk mengetahui kelayakan dan kepraktisan dari sebuah prototipe produk penelitian.

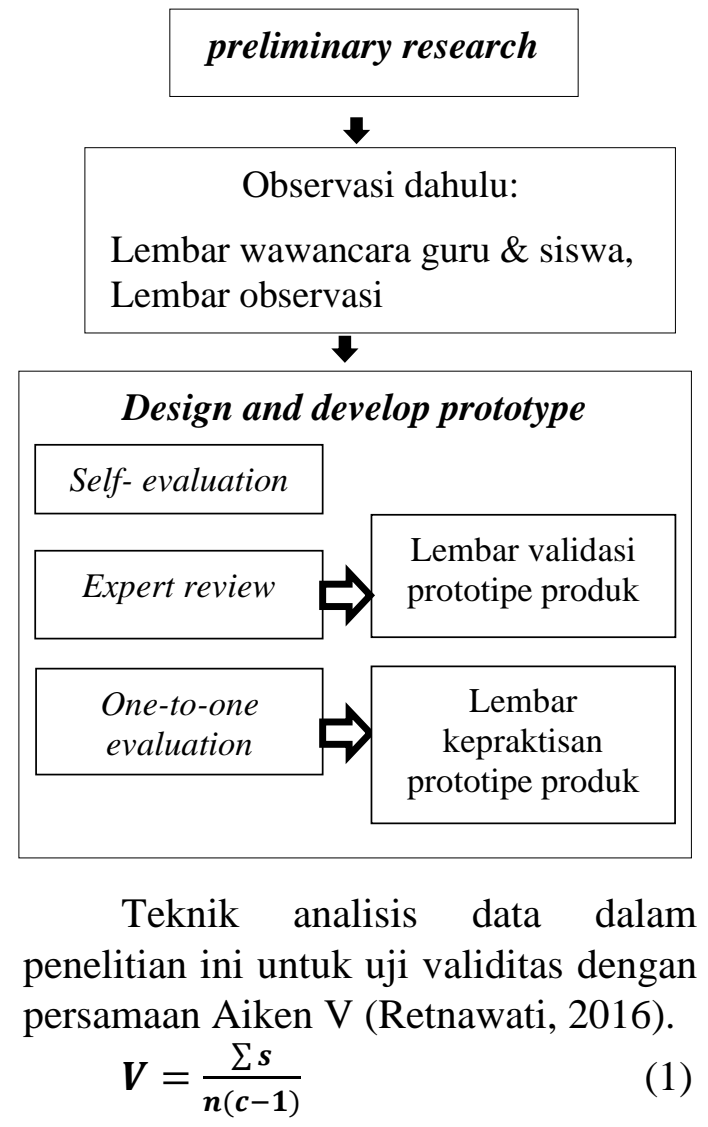

Indeks $\boldsymbol{V}$ ini nilainya berkisaran antara 0-1. Kriteria yang digunakan untuk menyatakan media, bahan ajar dan produk pembelajaran memiliki validasi yang memadai dapat dilihat pada tabel 1.

Tabel 1. Kategori validasi pengembangan produk dengan rumus Aiken $\mathrm{V}$

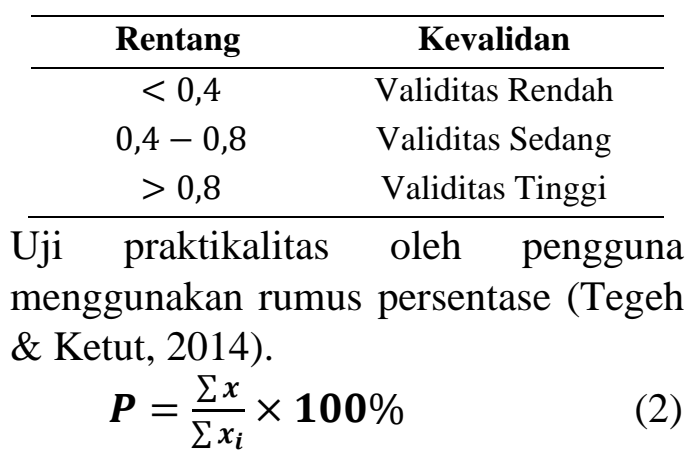


Tabel 2. Klasifikasi persentase peniliaian produk

\begin{tabular}{cc}
\multicolumn{2}{c}{ produk } \\
\hline Persentase \% & Kriteria \\
\hline $89 \geq \mathrm{P} \leq 100$ & Sangat Layak \\
$74 \geq \mathrm{P} \leq 89$ & Layak \\
$64 \geq \mathrm{P} \leq 74$ & Cukup Layak \\
$0 \geq \mathrm{P} \leq 64$ & Kurang Layak \\
$\mathrm{P} \leq 0$ & Tidak Layak \\
\hline
\end{tabular}

Untuk menentukan persentase ralat relatif dari hasil uji eksperimen dengan hasil teori menggunakan persamaan 3 .

$\boldsymbol{R}=\left|\frac{\text { eksperimen-teori }}{\text { teori }}\right| \times 100 \%$

\section{HASIL DAN PEMBAHASAN}

Penelitian ini membuat alat eksperimen, user manual dan modul praktikum untuk percobaan penentuan koefisien gaya gesek pada bidang miring berbasis induksi magnet. Alat yang digunakan menggunakan bahan akrilik dan viber, koefisien gesek benda yang akan dicari adalah koefisien gesek kinetis pada bidang miring dengan sudut kemiringan sebesar $30^{\circ}$. Rancangan alat dapat dilihat pada gambar 1.

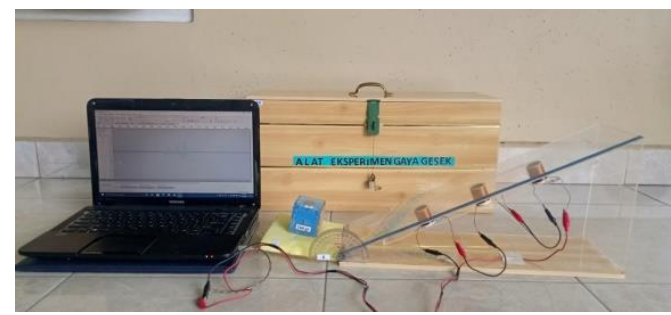

Gambar 1. Rancangan alat eksperimen gaya gesek bidang miring

Dari hasil uji eksperimen oleh pengguna didapatkan nilai koefisien gesek kinetis seperti pada tabel 3.

Tabel 3. Hasil data eksperimen gesek kinetis

\begin{tabular}{|c|c|c|c|}
\hline \multirow[b]{2}{*}{$\begin{array}{c}\text { Jarak } \\
(\mathbf{m})\end{array}$} & \multicolumn{3}{|c|}{ koefisien gaya gesek kinetis } \\
\hline & $\begin{array}{c}\text { Akrilik } \\
\text { \& } \\
\text { Kayu }\end{array}$ & $\begin{array}{c}\text { Akrilik } \\
\& \\
\text { Plastik }\end{array}$ & $\begin{array}{c}\text { Akrilik } \\
\qquad \& \\
\text { Akrilik }\end{array}$ \\
\hline 0.1 & 0.292 & 0.265 & 0.208 \\
\hline 0.05 & 0.034 & 0.178 & 0.309 \\
\hline
\end{tabular}

Berdasarkan tabel 3. menunjukkan bahwa hasil perhitungan alas permukaan kayu lebih besar dibandingkan dengan permukaan plastik dan akrilik. Sedangkan untuk jarak pehitungan koefisien gesek kinetis mempengaruhi besar gesekan yang terjadi pada benda dimana semakin dekat jarak benda maka semakin kecil gesekan yang terjadi. Diperoleh persentase ralat relatif akrilik dengan kayu sebesar 15\%, akrilik dengan akrilik sebesar $30 \%$ dan data hasil perhitungan koefisien gesek kinetis bahan akrilik dengan plastik sebesar 0.208 .

User manual merupakan panduan tata cara pemasangan alat eksperimen yang di dalamnya terdapat cover, kata pengantar, spesifikasi alat, daftar isi, bagian-bagian alat dan panduan pengguna. Hasil produk user manual dapat dilihat pada gambar 2 .
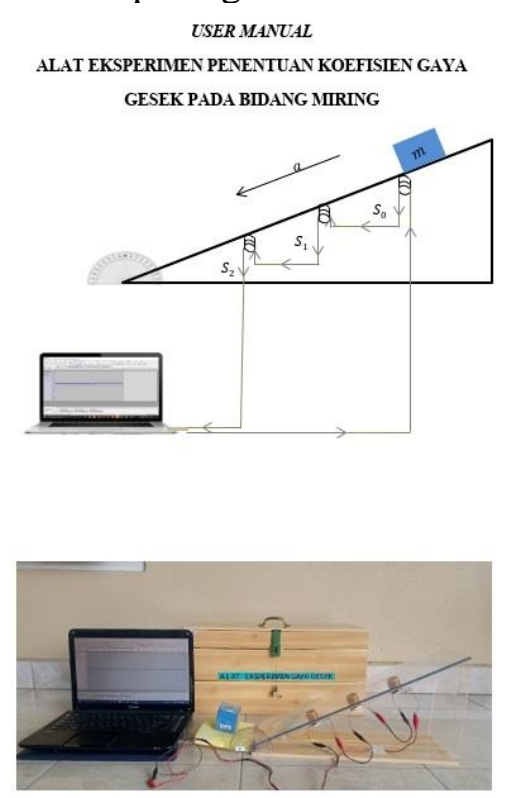

Gambar 2. Hasil produk user manual

Hasil uji validitas prototipe produk ahli/pakar, uji praktikalitas oleh guru dan peserta didik disajikan pada tabel 4, 5 dan tabel 6 . 
Tabel 4. Hasil uji validitas produk

\begin{tabular}{clc}
\multicolumn{3}{c}{ ahli/pakar } \\
\hline No & Aspek yang dinilai & $\begin{array}{c}\text { V } \\
\text { (Indek Validasi) }\end{array}$ \\
\hline 1 & $\begin{array}{l}\text { Ahli Media (Alat } \\
\text { Eksperimen) }\end{array}$ & 0,88 \\
2 & $\begin{array}{l}\text { Ahli Materi (User } \\
\text { Manual) }\end{array}$ & 0,86 \\
3 & $\begin{array}{l}\text { Ali Materi (Modul } \\
\text { Praktikum) }\end{array}$ & 0,83 \\
4 & Bahasa \\
& Rata-rata validitas & 0,87 \\
\end{tabular}

Berdasarkan tabel 4. diperoleh indeks validasi ahli media 0,88 terletak pada rentang > 8 dengan kriteria validitas tinggi. Pada ahli materi (user manual) diperoleh 0,86 dan ahli materi (modul praktikum) diperoleh 0,83 dengan kriteria validitas tinggi sedangkan ahli bahasa diperoleh validitas 0,87 dengan kriteria validitas tinggi. Sehingga hasil analisis produk dengan rata-rata 0,86 terletak pada rentang $>8$ dengan kriteria validitas tinggi.

Tabel 5. Hasil uji praktikalitas produk oleh guru

\begin{tabular}{clc}
\hline No & Aspek Yang dinilai & $\begin{array}{c}\text { Persentase } \\
(\%)\end{array}$ \\
\hline 1 & Alat Eksperimen & 81 \\
2 & User Manual & 86 \\
3 & Modul Praktikum & 79 \\
Rata-rata persentase & 82 \\
\hline
\end{tabular}

Berdasarkan tabel 5. hasil uji praktikalitas oleh guru diperoleh ratarata $82 \%$ dengan kriteria layak.

Tabel 6. Hasil uji praktikalitas produk oleh peserta didik

\begin{tabular}{clc}
\hline No & Aspek Yang dinilai & $\begin{array}{c}\text { Persentase } \\
(\%)\end{array}$ \\
\hline 1 & Alat Eksperimen & 79 \\
2 & User Manual & 77 \\
3 & Modul Praktikum & 79 \\
Rata-rata persentase & 78,33 \\
\hline
\end{tabular}

Berdasarkan tabel 6. hasil uji praktikalitas oleh peserta didik diperoleh rata-rata $78,33 \%$ dengan kriteria layak. Sehingga alat eksperimen penentuan koefisien gaya gesek pada bidang miring berbasis induksi magnet layak digunakan untuk praktikum peserta didik.

Hasil penelitian ini didukung beberapa penelitian relavan yang menyatakan bahwa alat eksperimen dan pendekatan eksperimen sangat baik digunakan dalam kegiatan pembelajaran guru, seperti hasil penelitian yang berjudul " Measurement of kinetic friction coefficient through magnetic induction using audacity application in physic learning" (Rohman et al., 2020), penelitian yang berjudul "Pengaruh luas permukaan benda terhadap koefisien gesek statis dan kinetis pada bidang miring dengan menggunakan video tracker" (Amirudin et al., 2018) dan penelitian yang berjudul "Miskonsepsi gaya gesek pada mahasiswa", dalam penelitiannya dilakukan analisis dan evaluasi terhadap konsep gaya gesek dan diberikan pelurusan materi mengenai konsep gaya gesek (Tiandho, 2018). Sedangkan perbedaan penelitian ini, yaitu pengukuran koefisien gaya gesek menggunakan bidang miring berbasis induksi magnet dan menggunakan bahan praktikum akrilik dan kayu. Penelitian ini berfokus pada pengukuran koefisien gaya gesek pada bidang miring berbasis induksi magnet dengan bantuan software Audacity yang dapat digunakan dalam proses pembelajaran.

\section{PENUTUP}

\section{KESIMPULAN}

Hasil penelitian ini menunjukkan nilai validitas yang diperoleh dari alat eksperimen dan sistem pendukung dengan rata-rata indeks validasi 0,86 
dengan kriteria validitas tinggi. Sedangkan hasil uji kepraktisan oleh guru diperoleh rata-rata persentase $82 \%$ dengan kriteria layak sedangkan uji kepraktisan oleh peserta didik diperoleh persentase $78,33 \%$ dengan kriteria layak. Persentase Ralat relatif akrilik dengan kayu diperoleh sebesar $15 \%$ dengan nilai koefisien gesek kinetis $\mu_{k}$ 0.292 , akrilik dengan akrilik $30 \% \mu_{k}$ 0.208 dan akrilik dengan plastik diperoleh $\mu_{k}$ 0.265. Berdasarkan data tersebut dapat disimpulkan bahwa alat eksperimen penentuan koefisien gesek kinetis yang dikembangkan bersifat valid dan praktis untuk digunakan sebagai media pembelajaran oleh pengguna.

\section{SARAN}

Pengembangan alat eksperimen penentuan koefisien gesek kinetis pada bidang miring berbasis induksi magnet masih ada kekurangan dalam hasil uji coba, sebagaimana ralat relatif yang dihasilkan cukup besar dikarenakan beberapa faktor. Maka dari itu untuk peneliti selanjutnya dapat mencari dan meminimalisir besarnya ralat relatif yang dihasilkan oleh peneliti.

\section{UCAPAN TERIMAKASIH}

Terimakasih kepada validator yang telah bersedia meluangkan waktu untuk memberikan penilaian dan saran untuk pengembangan alat eksperimen gaya gesek yang telah dibuat oleh peneliti sehingga menghasilkan produk sesuai dengan saran yang diberikan oleh validator.

\section{REFERENSI}

Aini, Q., Rofiqah, S. A., \& Effendi, E. (2021). Metode Praktikum dengan Media Animasi Powerpoint: Pengaruh terhadap Motivasi Belajar Peserta Didik SMA Negeri
1 Belitang. ... : Journal Education

of Young ..., 2(1), 23-28.

http://www.jsr.stkipnurulhuda.ac.i

d/index.php/u-

teach/article/view/33

Alismail, H. A., \& McGuire, P. (2015).

21 St Century Standards and Curriculum: Current Research and Practice. Journal of Education and Practice, 6(6), 150-155. http://files.eric.ed.gov/fulltext/EJ1 083656.pdf

Amirudin, D., Astro, R. B., Mufida, D. H., Humairo, S., \& Viridi, S. (2018). Pengaruh Luas Permukaan Benda Terhadap Koefisien Gesek Statis Dan Kinetis Pada Bidang Miring Dengan Menggunakan Video Tracker. Prosiding Seminar Nasional Fisika (E-Journal) SNF2018, VII, $1-7$. https://doi.org/10.21009/03.snf201 8.01.pe. 12

Astuti, I. A. D., Dasmo, D., \& Sumarni, R. A. (2018). Pengembangan Media Pembelajaran Berbasis Android Dengan Menggunakan Aplikasi Appypie Di SMK Bina Mandiri Depok. Jurnal Pengabdian Kepada Masyarakat, 24(2), 695-701. https://doi.org/10.24114/jpkm.v24i 2.10525

Djamaluddin, A. (2014). Filsafat Pendidikan. Istiqra': Jurnal Pendidikan Dan Pemikiran Islam, 1(2), 129-135. https://jurnal.umpar.ac.id/index.ph p/istiqra/article/view/208/181

Fitrianto, M. B., Darmanto, D., \& Imam, S. (2015). Pengujian Koefisien Gesek Permukaan Plat Baja ST 37 Pada Bidang Miring Terhadap Viskositas Pelumas Dan Kekasaran Permukaan. 
Momentum, 11(1), 13-18.

Harahap, M., Firman, F., \& Ahmad, R. (2021). Penggunaan Social Media dan Perubahan Sosial Budaya Masyarakat. Edukatif: Jurnal Ilmu Pendidikan, 3(1), 135-143. https://doi.org/10.31004/edukatif.v $3 i 1.252$

Irwandani, Latifah, S., Asyhari, A., Muzannur, \& Widayanti. (2017). Modul Digital Interaktif Berbasis Articulate Studio'13 : Pengembangan pada Materi Gerak Melingkar Kelas X. Jurnal Ilmiah Pendidikan Fisika Al-Biruni, 06(2), 221-231. https://doi.org/10.24042/jipfalbirun i.v6i2.1862

Kebudayaan, M. P. (2003). Undangundang No.20 Tahun 2003 tentang Sistem Pendidikan Nasional.

Leman, D., \& Lubis, C. P. (2021). Pemanfaatan Video Pembelajaran Dengan Aplikasi Camtasia dan Audacity. J-PEMAS STMIK, 2(2), 20-27.

http://jurnal.sar.ac.id/index.php/JPEMAS

Mardianti, I., Kasmantoni, \& Walid, A. (2020). BIO-EDU : Jurnal Pendidikan Biologi Pengembangan Modul Pembelajaran IPA Berbasis Etnosains Materi. Bio-Edu: Jurnal Pendidikan Biologi, 5(2), 97-106.

Muzaky, A. F., \& Handhika, J. (2015). Penggunaan Alat Peraga Sederhana Berbasis Teknologi Daur Ulang untuk Meningkatkan Pemahaman Konsep Materi Vektor dalam Kelas Remedial SMKN 1 Wonoasri Tahun Pelajaran 2014/2015. Prosiding Seminar Nasional Fisika Dan Pendidikan Fisika (SNFPF), 129-134.
Nurseto, T. (2012). Membuat Media Pembelajaran yang Menarik. Jurnal Ekonomi Dan Pendidikan, $8(1)$, 19-35. https://doi.org/10.21831/jep.v8i1.7 06

Plomp, T. (2013). Educational design research: An introduction. Educational Design Research, 1150 .

Rakhmawati, S., Muspiroh, N., \& Azmi, N. (2016). Analisis Pelaksanaan Kurikulum 2013 Ditinjau dari Standar Proses dalam Pembelajaran Biologi Kelas X di SMA Negeri 1 Krangkeng. Scientiae Educatia: Jurnal Sains Dan Pendidikan Sains, 5(2), 156164.

www.syekhnurjati.ac.di/jurnal/inde x.php/sceducatia

Retnawati, H. (2016). Analisis kuantitatif instrumen penelitian. Parama Publishing.

Rohman, F., Azwir, Y., \& Fauzan, A. (2020). Measurement of kinetic friction coefficient through magnetic induction using audacity application in physics learning. International Journal of Online and Biomedical Engineering, 16(3), 117-125. https://doi.org/10.3991/IJOE.V16I 03.12553

Suyatno. (2009). Menjelajah Pembelajaran Inovasi. Masmedia Buana Pustaka.

Tegeh, M., \& Ketut, P. (2014). Model penelitian pengembangan. Graha Ilmu.

Tiandho, Y. (2018). Miskonsepsi gaya gesek pada mahasiswa. Pendidikan Fisika Dan Keilmuan (JPFK), 4(1),

1-9. 
https://doi.org/10.2572/jpfk.v4i1.1

814

Walid, A. (2017). Strategi Pembelajaran IPA. Pustaka Pelajar.

Widayanti, Yuberti, Irwandani, \& Hamid, A. (2018). Pengembangan Lembar Kerja Praktikum Percobaan Melde Berbasis Project Based Learning. Jurnal Pendidikan Sains Indonesia, 06(01), 24-31. https://doi.org/10.24815/jpsi.v6i1.1 0908 